\title{
11.11 EVALUATION OF THE TOWN ENERGY BALANCE (TEB) SCHEME WITH DIRECT MEASUREMENTS FROM DRY DISTRICTS IN TWO CITIES
}

\author{
V. MASSON ${ }^{1}$, C. S. B. GRIMMOND ${ }^{2}$ and T. R. OKE ${ }^{3}$ \\ ${ }^{1}$ METEO-FRANCE, Toulouse,${ }^{2}$ Indiana University, Bloomington, ${ }^{3}$ University of British Columbia, Vancouver
}

\section{INTRODUCTION}

The Town Energy Balance (TEB) model of Masson (2000) simulates turbulent fluxes for urban areas using generic canyon geometry to resolve energy balances for walls, roads and roofs. An evaluation of TEB is presented using measured surface temperatures $(T)$ and local-scale energy balance fluxes for two "simple" urban sites: a downtown area within the historic core of Mexico City (stone buildings 5-6 stories in height, Oke et al.1999), and a light industrial site in Vancouver, (flatroofed, single-story warehouses, Grimmond and Oke 1999, GO99). TEB is run and evaluated for 14 days in Vancouver (August 1992) and 6 days in Mexico City (December 1993) (Masson et al. 2002). Both sites are almost dry resulting in minimal measured latent heat fluxes (Grimmond and Oke 2002).

\section{IMPLEMENTATION OF TEB}

The Masson (2000) scheme was slightly modified, notably with respect to formulation of the aerodynamic resistances (those shown with thick lines on Fig. 1). The road resistance now follows a roughness length formulation. This was based on analyses of the Vancouver site, where roads are important and remotely-sensed (RS) road T allowed discrimination between different forms. The roughness length of the road is set to $50 \mathrm{~mm}$, this includes the road surface and the presence of street obstacles of the order of $1 \mathrm{~m}$. The internal layer $\mathrm{T}$ of roof and wall are now linked to building interior $\mathrm{T}$ using a resistance $\left(0.123 \mathrm{~K} \mathrm{~m} \mathrm{~W}^{-1}\right)$ commonly used in building insulation.

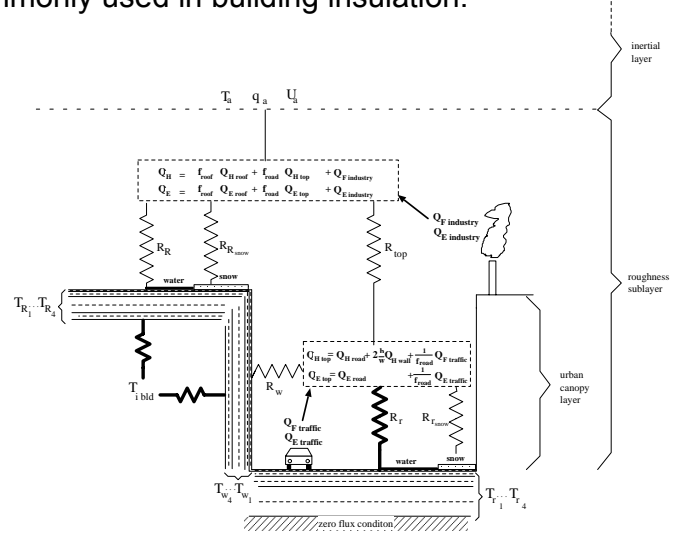

Figure 1: TEB aerodynamic resistances network.

\section{RESULTS}

\section{Mexico City}

The surface T observations were conducted in two

Corresponding author: V. Masson, CNRMS, 31057

Toulouse cedex France email: valery.masson@meteo.fr perpendicular canyons; whereas TEB computes one road and one wall surface $T$, that are independent of direction. Comparisons are made against the average of field values. The general diurnal evolution of roof and road $T$ are correctly reproduced by TEB.

TEB is evaluated using measured energy fluxes: net all-wave radiation, $Q^{*}$, sensible heat flux, $Q_{H}$ and storage heat flux, $\Delta Q_{S}$ (Fig. 2). At night, observed $Q^{*}$ averages $-103 \mathrm{~W} \mathrm{~m}^{-2}$, while TEB reaches only $-82 \mathrm{~W} \mathrm{~m}^{-2}$.

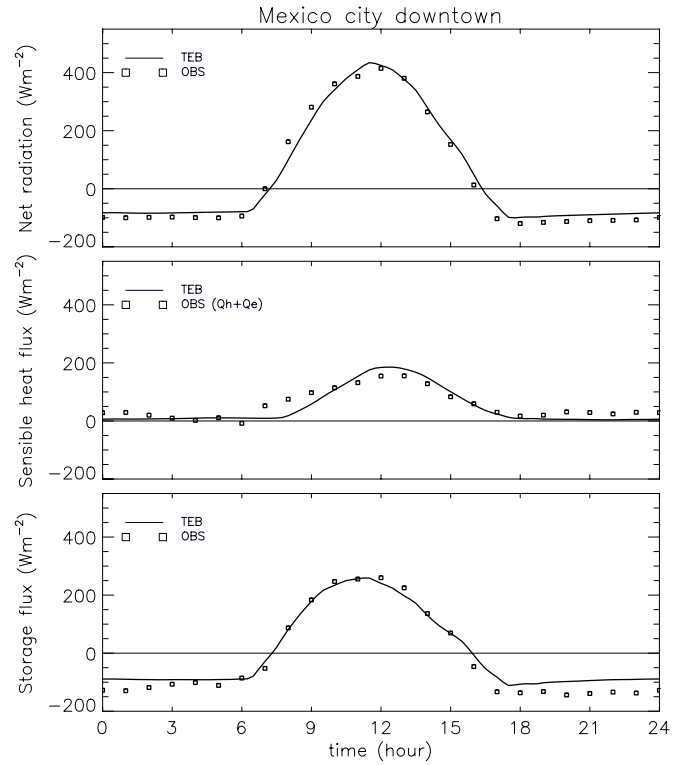

Figure 2: Mean diurnal cycle of surface energy balance fluxes for the Mexico City site.

The observed daytime $\Delta Q_{s} / Q^{*}$ ratio at the central city site is very high (0.58); storage is more efficient than convection over this densely built-up district. This can probably be attributed to the thermal properties of the construction materials, the large 3-D surface area exposed in this area of deep canyons, and the relatively light winds during the observation period. (GO99). TEB reproduces this result well; the simulated ratio is also 0.58 . The observations show very little hysteresis between $\mathrm{Q}^{*}$ and $\Delta \mathrm{Q}_{\mathrm{S}}$ (G099), and TEB also reproduces this well (Masson et al. 2002).

In summary, TEB is able to reproduce correctly most of the behavior of the fluxes typical of the Mexico central city site, including the low winter $Q^{*}$, the large daytime heat uptake by the urban fabric, and the positive $Q_{H}$ at night.

\subsection{Vancouver Light Industrial}

The micro-scale roof $\mathrm{T}$ shows a large diurnal range. TEB simulates the general pattern well, but with a smaller amplitude (Fig. 3). The TEB "wall" T, evaluated 
against the mean of the observed wall $\mathrm{T}(\mathrm{N}, \mathrm{E}, \mathrm{S}$ and W-facing), gives good agreement on sunny days. However, it seems the temporal history of warming over the day, and especially its disruption by cloud, may be relevant controls that TEB does not fully incorporate. TEB road T simulates the local-scale RS T well (Fig. 3).
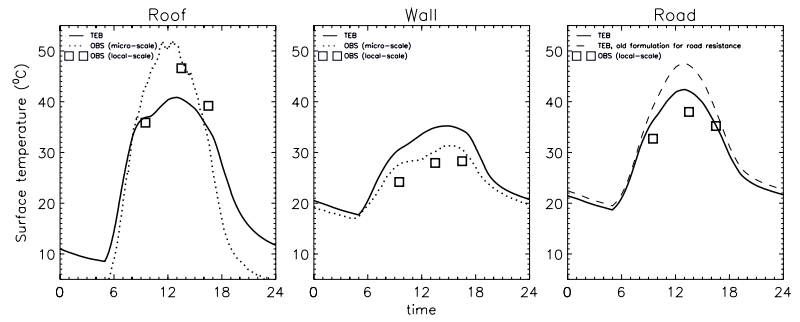

Fig 3: Surface temperatures at the Vancouver site (YD 228). Local-scale $T$ from remote sensing, microscale $\mathrm{T}$ based on individual facet IRT observations.

The observed energy fluxes show a relatively large $\Delta Q_{S}$ during the night. This creates a positive $Q_{H}$ during the early evening. TEB is able to simulate this nocturnal pattern. During the day, for YDs 224, 225, 232 - 236 there is reasonable correspondence between the predictions of TEB and the measured fluxes. On the other days, however, TEB significantly over-predicts $Q_{H}$ and under-predicts $\Delta Q_{\text {s. }}$.

When comparing modeled and measured data it is important to consider measurement uncertainties. Storage is computed here as the residual of the measured energy balance, and thus errors in any of the other fluxes, accumulate in $\Delta Q_{S}$ (G099). Since TEB simulates both the nocturnal heat release and the surface $\mathrm{T}$ well, this indicates that the model has stored the correct amount of energy during the day. For YD 226-231 the daytime observations of $\Delta Q_{S}$ are much larger than those predicted by TEB, while similar values are found at night.

Anticipated anthropogenic heat fluxes at this site are expected to be small $\left(<20 \mathrm{~W} \mathrm{~m}^{-2}\right)$, and cannot explain the differences. More interestingly, on days when TEB does better, winds are from the south and south-west, veering to westerly flow only in the late afternoon. When observations and TEB are different, wind directions are mainly westerly and a sea breeze may affect the site. Under these circumstances it is possible that the lack of ability to evaluate the advection term in both the measurements and the model results prevents an appropriate comparison of the fluxes.

\section{CONCLUSION}

Evaluation of TEB using field data from two dry urban areas, each with very different structure, suggests that overall the model performs well. The agreement with the measurements give some support to one of the main simplifications of TEB: the use of only one wall $T$.

This evaluation can help in the interpretation of existing field data and the design of future observational programs. For example, the timing of clouds relative to canyon geometries and the role of advection need further investigation.

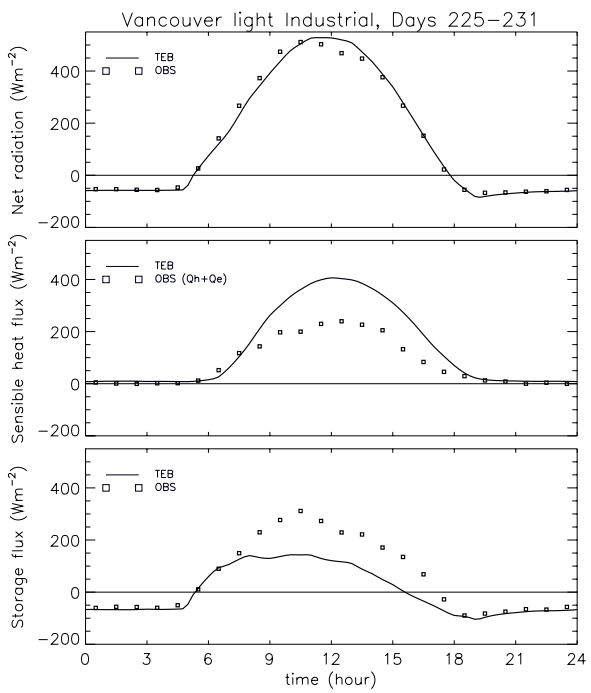

Fig 4: Mean diurnal cycle of surface energy balance fluxes for the Vancouver site (YD 225-231).

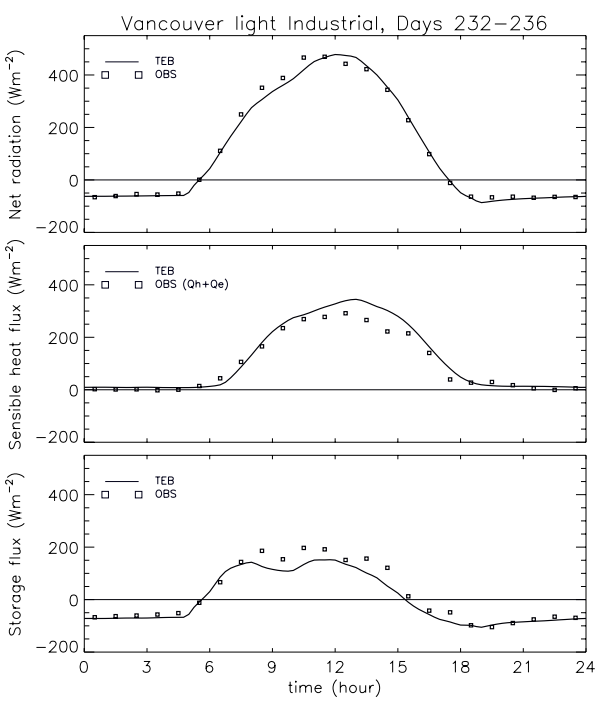

Fig 5: Mean diurnal cycle of surface energy balance fluxes for the Vancouver site (YD 232-236).

\section{Acknowledgements}

Funded by CNRS and NSF 0095284.

\section{References}

Grimmond C. S. B. \& Oke T. R. 1999: Heat storage in urban areas: local-scale observations and evaluation of a simple model JAM, 38, 922-940.

-- \& -- 2002: Turbulent heat fluxes in urban areas: Observations and local-scale urban meteorological parameterization scheme (LUMPS), JAM in press

Masson, V. 2000: A physically-based scheme for the urban energy budget in atmospheric models, BLM, 94, 357-397.

--, C.S.B. Grimmond \& T.R. Oke Evaluation of the Town Energy Balance (TEB) scheme with direct measurements from dry districts in two cities. JAM, in review

Oke, T. R. R. Spronken-Smith, E. Jauregui, and C.S.B. Grimmond. 1999: The energy balance of central Mexico City during the dry season. AE, 33, 3919-3930. 